\title{
Active Learning: From Flipped Lectures to the Covid-19 Era
}

\author{
Paul Wyatt*
}

\begin{abstract}
The use of flipped lectures and Active Learning has been explored in first year lectures for several years. Learning Catalytics software has been used to facilitate Peer-2-Peer learning in the Active Learning sessions. Several lessons were learned during these sessions which were important as we moved into delivering online material much more comprehensively. Bringing interaction to the lectures that were delivered live (synchronous sessions) was important to staff. Several technical solutions for producing online videos of high quality were brought into broader use. New teaching formats including a 'radio show' have been introduced to ensure that rich interaction with the students is possible with large groups.
\end{abstract}

Keywords: Active Learning $\cdot$ Flipped $\cdot$ Online $\cdot$ Peer-2-Peer $\cdot$ Radio

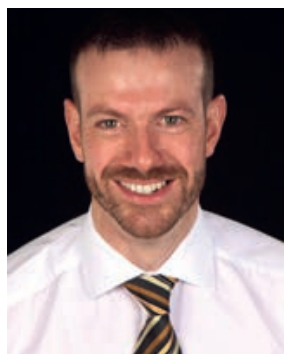

Professor Paul Wyatt is an organic chemist and Professor of Teaching \& Learning in the School of Chemistry at the University of Bristol. He is also a Senior Academic Developer for the University of Bristol. $\mathrm{He}$ is the co-author of four chemistry textbooks and has contributed to revision of the chemistry curriculum for the International Baccalaureate. He was the Director of Undergraduate Studies for some thirteen years and Director of the Bristol ChemLabS project. He has a keen interest in teaching innovation at Bristol and beyond.

\section{Active Learning}

Active Learning has emerged as a far more effective way for students to learn than the more traditional and 'passive' approach. With Active Learning students do something to actively engage with work and problems rather than just being on that passive receiving end. ${ }^{[1,2]}$ Although effective, whether students like it or not is another matter. Sometimes they enjoy the interaction but in some cases they can prefer the more structured and familiar approach. In student surveys, student satisfaction is sometimes used by institutions as a proxy for quality. So if the students don't like a new approach then that can present an obvious impediment to the innovative lecturer who has an eye on scores from students. Although actual learning is demonstrated to be better with an Active Learning environment, students can feel like they learn less. ${ }^{[3]}$ Similarly, many students 'like' lecture capture but whether it is good for their education will largely depend on how they use it. In the best-case scenario, students attend the real lecture and then use the recordings to review content later. In the worst-case scenario, students don't attend the lectures and, although they may have good intentions, never get round to watching the recordings either - a modern version of those 'photo-copied lecture notes' the student is reassured to have the notes even if they go forever uninspected.

A study in 2010 found that students' brainwaves were at their most active when the students were asleep and at their least active when the students were a) watching TV and b) in class. Combining TV and class sounds rather like lecture capture! ${ }^{[4]}$ The point is that

${ }^{*}$ Correspondence: Prof. P. Wyatt, E-mail: paul.wyatt@bris.ac.uk,

School of Chemistry, University of Bristol, Cantock's Close, Bristol, BS8 1TS, UK technology on its own is not going to solve anything and simply moving lectures online is unlikely to deliver a very good result. But it could feature as part of a considered educational diet and larger strategy to engage students. Interaction has to be an important part of what we deliver.

Sections 2 and 3 that follow are a personal account of attempts by the author to improve his own teaching in first year lectures between 2016 and 2019. Section 4 explains how those experiences and lessons found wider application in 2020 as the School of Chemistry as a whole moved into much more widespread online teaching.

\section{What We Changed}

In 2016, the attempt to improve the engagement by students in lectures involved a three-pronged approach - upgrading the audiovisual equipment from visualizer to iPad, introducing the flipped lecture to replace half of the traditional lectures and using state-ofthe-art polling software. This would bring Active Learning to the lecture course as well as improving the audio-visual experience.

\subsection{Using an iPad instead of a Visualiser}

Plugging an iPad into the VGA port at the front of a lecture theatre instead of using the visualiser gives a vastly superior image in the first place - perfectly in focus with colours rendered properly and with the added bonus that the lecturer's hands do not get in the way at any time.

\subsection{Flipping the Lectures}

In the traditional format there had been two real lectures a week for four weeks. This was changed to one real lecture followed by the flipped online lecture. The second real lecture session was then used, not for a lecture, but to interact with the students. This interaction was facilitated by their mobile phones and polling software. From 2017 onwards, in the online pre-recorded lectures, structures were drawn on an iPad with narration. Interestingly, when students say they like watching pre-recorded lectures because they can watch them at their own pace they do not always mean they slow them down - often it means they speed them up!

The idea with flipping only half the lectures was two-fold. Firstly it means that the students are anchored in something familiar for half of the course. Since this will be the first time they have encountered a course that teaches with flipped learning it keeps it from being too unfamiliar. Secondly, having one real face-to-face 
lecture every week helps the students keep in sync with the class - it reduces the risk that they get increasingly behind with videos that they will 'watch later'.

\subsection{Using Sophisticated Polling Software}

We want to get the students talking to each other. More than this the software facilitated getting students with different answers talking to each other to maximise Peer-2-Peer learning. In this way we hoped to make the time with the lecturer richer and an opportunity for discussion as well as introducing a strong component of Peer-2-Peer learning. We used 'Learning Catalytics' software which is marketed by Pearson. While there is lots of different polling software available and much of it free, this software allowed us to map the lecture theatre. Students log in on their phones or other devices and input their seat from the seating plan. The software thus knows exactly where everyone is sitting and at the right time can tell them who they should be talking to (by name) and precisely where that person is sitting. Another useful feature of the software is the 'heat map' of the lecture theatre that shows the lecturer, in real time, how the student audience is responding.

\subsection{What Were the Results?}

The idea with Peer-2-Peer learning is that both parties benefit. One student has it explained to them by another who 'gets it'. Meanwhile the one who 'gets it' has to marshal their thoughts carefully to explain to someone who does not - thus embedding their own understanding. Typically students were asked to vote on a question individually (Round 1). They were then put into groups based on their answers to discuss it for 90 seconds or so. They were then asked to vote again. Fig. 1 shows a screenshot of an example from a question about the $\mathrm{S}_{\mathrm{N}} 2$ reaction. While the first round has fairly good scores for the correct questions, only $43 \%$ of the class got all three correct. On this occasion, no further information was given to them before their discussion - it was up to them alone to discuss their answers and then vote again. In the second round, $76 \%$ of the class got all three answers correct.
Inspection of Fig. 1 shows a marked improvement that many find persuasive. However, despite this fairly clear evidence, not all staff were convinced and there was a suggestion that improved results are merely the result of students converging on the right answer. In other words, doing what their friends do. Whether students really do improve their understanding through peer learning or are just influenced by their peers is something that has been studied in other subjects by the use of subsequent isomorphous questions (i.e. the same concepts are tested in a different setting) on an individual basis following a group discussion. The subject was undergraduate genetics. The evidence clearly showed that learning by peer discussion is real and can be applied (transferred) to other questions. ${ }^{[5]}$

It is, of course, up to the lecturer how the session runs. Sometimes revealing to the class only that most people got the answer wrong in Round 1 can lead to quite a buzz of excitement as we move into the discussion of Round 2. Early feedback from students demonstrated that students then want the correct answers explained just as much as the wrong answers. In the best cases, where a couple of confident individuals in the class break the ice, the sessions can develop into being inquisitive, student-led and free-flowing.

\subsection{What Did the Students Think?}

On a typical Likert scale, $74 \%$ of students agreed or agreed strongly that they enjoyed using the software while $63 \%$ agreed or agreed strongly that they felt they had learned well using it. Here are some typical comments from students -

"These have been my favourite lectures so far this year, I have really enjoyed them and I've been more engaged with them than with any lectures so far this year. It's impossible to not actively listen. These have been the only lectures that have seemed like they're trying to get me to learn the information instead of just giving me information to then go away and learn."

"The online videos are effective at conveying the information appropriately as the speed of the videos can be varied and I can go through it at my own pace."

\section{learning|catalytics"}

$$
\text { Courses Questions Classrooms Training and Support Help Feedback }
$$

\section{$\underline{\text { My Courses }}>$ Reactivity 2018-19 $>$ Unfamiliar Reactions \& SN2 $>$ Session 46966613 \\ 团 Download results \\ - Attendance information $\square$ Messages $\times$ Delete data}

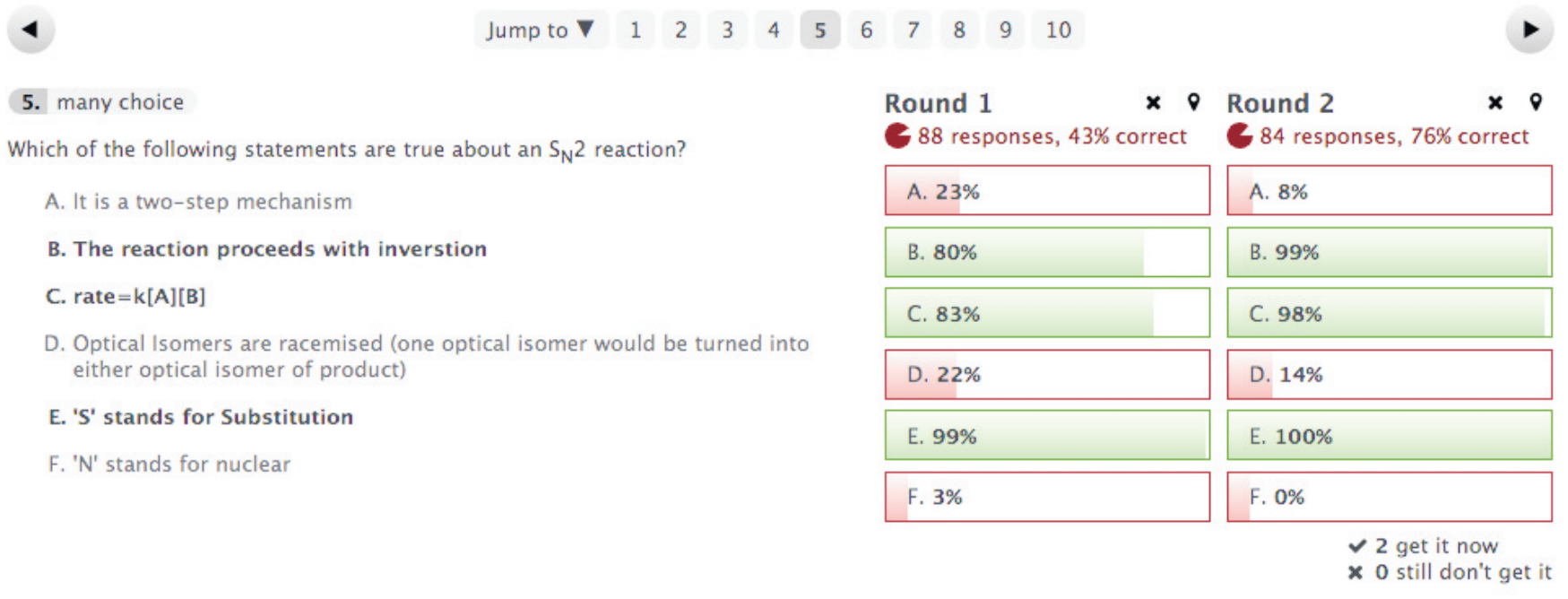

Fig. 1. A question from a flipped lecture. In Round 1 students vote individually. They then discuss their answers in groups of three or four students. In Round 2 they vote again. 
"The interactive sessions keep my attention better than any other lectures. I feel I learn a lot more through the interactive sessions."

\section{Common Criticisms and Lessons Learned}

\subsection{Isn't this just more Work in the Course?}

This is a comment that comes from staff more than the students. The worry is that if the students now have videos to watch in their own time then they must be doing more work. But this is not necessarily the case. If we accept that students have to do some personal study at some point then all we have done is move that into a formal teaching slot where they can interact. We really have flipped the lecture and the personal study. For some this will be more efficient than trying to make sense of things on their own. For students who do not normally do any personal study (until exam season anyway) then it will be extra work but they possibly would benefit the most from the structure.

\subsection{The Videos}

In the first year that this format was tried, lecture capture videos from the previous year were used as the online material. That this was simply not acceptable was a lesson learned quickly. While it might be satisfactory in addition to the main lecture, as the principal mode of delivery it was not good enough for several reasons - the frame rate of capture was rather low and the audio quality was poor and tended to pick up all the coughing and ambient noise in the lecture theatre. Students complained too (a lot) about the poor quality. For future years, the online videos were specially prepared to a high standard using an iPad as the writing medium and ScreenFlow as the capture/editing software. A high-quality USB condenser microphone with shock-mount and pop filter was used to ensure high quality noise-free audio. A soft towel laid across a hard desk surface is also surprisingly effective at improving the sound. Students never complained about audio/ video quality again.

\subsection{Does it always Work?}

As others have found, just because flipped lectures have worked well for three years does not mean they will the following year. ${ }^{[6]}$ In November 2019 the flipped course did not receive such a good reception from the students. Since the lecturer and materials and format were just the same it was initially difficult to identify where the problem was. The only difference we could think of was that there had been more of an introductory session in previous years where the students had had more time to play and familiarise themselves with the software. This session did not happen in November 2019 and so possibly some students struggled with the software initially. Although they rapidly got the hang of it, it seems the damage was done. While $76 \%$ of first year students agreed or strongly agreed (in 2018) that the course should be run that way next year, this view fell to $35 \%$ with first years in 2019.

\subsection{Summary of Lessons Learned 2016-2019}

1. Make sure all the students get the opportunity to explore the software properly and have it explained to them before they go live.

2. Make sure the videos are recorded specially to a high standard and,...

3. ...use a quality microphone and good acoustic environment to do so.

4. Keep the videos quite short so the students can maintain focus and readily get to the part they want.

5. It is as well to be very clear about a task. What exactly do they need to do and how long have they got to do it?

6. Be really clear with the students about the format of the course. Again, what do they need to do and by when?
7. Tell the students why you are doing things this way. Explain that it's about better learning etc. In the absence of an explanation students can get the idea that it is more about monitoring attendance.

8. And of course, do NOT use the logins from the students to monitor lecture attendance - they will resent it and not engage with the process.

\section{Moving Online in the Covid Era in $\mathbf{2 0 2 0}$}

As we responded to the Covid-19 crisis it naturally became immediately obvious that much teaching needed to be moved online. Keeping students engaged in a remote teaching environment was, and continues to be, a huge challenge. Bringing Active Learning to the online arena will clearly be more stimulating and educational than just giving the students a load of videos to watch. All of the 'lessons learned' in our experimentation with flipped lectures were applied to the new online environment. For staff accustomed exclusively to a traditional approach to lecturing, necessity became the mother of professional development and all of us learned something new as we moved to the new way to delivery.

\subsection{Addressing the 'Lessons Learned'}

1. We put together a 'Digital Welcome' set of videos for new students. These tell the students what to expect in terms of teaching online and what we will be doing in-person including the arrangements for laboratories. There is an interactive presentation for them to work through about learning online. The topics also include 'code of conduct' online and shows them how to navigate the online resources. There is even advice on reducing screen time. There is a video to watch which shows them exactly how to use Zoom so they could get familiar with this in advance of any lectures. Live sessions were also held for each year group to describe the particular flavour for that class.

2. Lectures were recorded specially. Several colleagues decided to invest in Telestream's 'ScreenFlow' to record their lectures by screen capture. This software offers the advantage of being able to edit the video and audio and even add text boxes and its own animations which is very helpful. Some staff took advantage of these animation features of ScreenFlow to enhance their presentation in 'post-production'. Other staff narrated PowerPoint slides while some even went into the empty lecture theatre to record on the visualiser using desktop lecture-capture software.

3. Any staff member who invested in a good quality microphone (a USB condenser mic) and took the effort to use a shock mount and pop filter was stunned by the profound difference it made to their recordings. Good quality audio is the most important part of an online presentation and the easiest thing to get right.

4. Videos are kept to bite-sized chunks of 10 minutes or so. Usually this is sufficient to cover a particular topic and students and staff alike are liberated from the 50 minute slot which may not be ideal to cover a selection of topics. No longer do we need to start a topic mid-way through because that is where time ran out last time.

5. While Learning Catalytics was a great way to get students into local breakouts in a lecture theatre, alternatives were needed online. A variety of tools have been used by different staff to engage students in the live sessions. These have included Turning Point, Mentimeter and Padlet. What has proven to be quite effective is the timed-response to questions - students get more marks for answering more quickly. The 'marks' are only for fun purposes of competition between the anonymous participants but keep the pace moving.

6. The students can find online, at the top of the first page, a timetable of everything they need to do on a week-by-week 
basis. With so many different activities taking place this is vital for them to keep track. For first years we also prepared a week-by-week checklist so they could be assured they had not missed anything.

7. \& 8. The online videos and the introductory lectures engaged with the topic of 'why' we are doing things the way we are as much as we could. Because the introductory lectures are live the students can ask questions.

\subsection{A new live Format - the 'Phone-In' Radio Show}

There are reasons why the world of radio does things the way it does. Radio has had decades to think about the way you engage and audience you cannot see. While we might also have webcams these days, the interaction has more in common with radio than it does with television. In this format, all lectures in a course are delivered asynchronously and online. Then every week there is a live session with the lecturer. This session is deliberately called a 'radio show' in order to give the students an idea of what to expect. They are all familiar with the phone-in radio format where listeners phone in with questions while other members of the audience just tune in to listen. Using the name 'workshop' or 'seminar' would give no idea of what might take place. Two staff are needed to run the radio show - the main host and someone to manage the student questions - the 'chat wrangler' as they have come to be called. The dialogue between the host and the chat wrangler means there are never any awkward silences and an informal atmosphere can be established. The students can post their questions to the whole room if they wish but most prefer to privately message the chat wrangler. The chat wrangler will verbally pose questions to the host that come in from students (or sometimes reply directly by message to the questioner if the question is not going to be aired). The host is casting the iPad via Zoom to the whole audience and drawing with a stylus. Chemical structures are thus readily communicated live as questions are answered. The host provides the chat wrangler with a couple of questions in advance. This is just in case the students are a bit slow coming forwards with questions or to get things going. In our experience, these questions combined with those that arise from the students are just enough to fill the session so it is worth planning ahead.

\subsection{What do the Students think and what next?}

Clearly the students are finding the current situation very challenging. While the School of Chemistry has managed to run laboratories for some years, the students miss the in-person face-toface contact. They are, however, very appreciative where efforts have been made by staff. Here were some answers to the survey question "The most engaging thing for me has been..."

"The online synchronous sessions where the lecturers are keen to get you to participate and encourage engagement through programmes such as Padlet."
"Using Mentimeter as a way of assessing content. I have found that I have absorbed more information than I would have done in in-person lectures because I can go back and relearn things easily."

"Lecturers have tried really hard to make lectures manageable, easy to follow and engaging and so all asynchronous have been well-done."

"I really like the asynchronous sessions as I can pause, rewind and rewatch the videos. I can take more time to go through the videos if I need to and look into subjects/key points I don't quite understand as I go through the videos."

"Synchronous lectures where the lecturer just answers questions that students have had about the course and explain things we haven't understood."

It is likely that some of the formats explored in the Covid-era will continue once normality is restored. The radio show is already proving popular with students. Students are not as inhibited as they are when in front of a lecture theatre full of their peers and, additionally, a single confident student cannot dominate the group. From a staff point of view it is more effective and more efficient than more traditional 'office hours' where the same question tends to be asked and answered by staff multiple times. We still have more to learn. For example, when recording a video resource it is all too easy for us to lecture to our class of 200 when it might be more engaging for us to do what late-night radio hosts do and direct our broadcast to an audience of one person. In any case, when we return to more normal times, those times will be better if they include the IT-based solutions we wish we had thought to introduce years ago.

Received: November 15, 2020

[1] L. Deslauriers, E. Schelew, C. Wieman, Science 2011, 862, 33.

[2] C. Wieman, 'Improving How Universities Teach Science' Harvard, 2017.

[3] L. Deslauriers, L. S. McCarty, K. Miller, K. Callaghan, G. Kestin, Proc. Natl. Acad. Sci. USA 2019, 19251, 116.

[4] M.-Z. Poh, N. C. Swenson, R. W. Picard, IEEE Trans. Biomed. Engin. 2010 , $57,1243$.

[5] M. K. Smith, W. B. Wood, W. K. Adams, C. Wieman, J. K. Knight, N. Guild, T. T. Su, Science $\mathbf{2 0 0 9}, 323,122$

[6] C. L. Jarvis, $C \& E N$ 2020, January 20, 23.

\section{License and Terms}

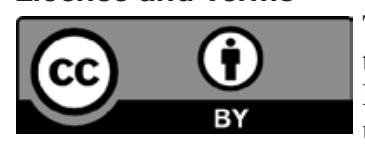

This is an Open Access article under the terms of the Creative Commons Attribution License CC BY 4.0. The material may not be used for commercial purposes.

The license is subject to the CHIMIA terms and conditions: (http:// chimia.ch/component/sppagebuilder/?view=page $\& i d=12$ ).

The definitive version of this article is the electronic one that can be found at https://doi.org/10.2533/chimia.2021.14 